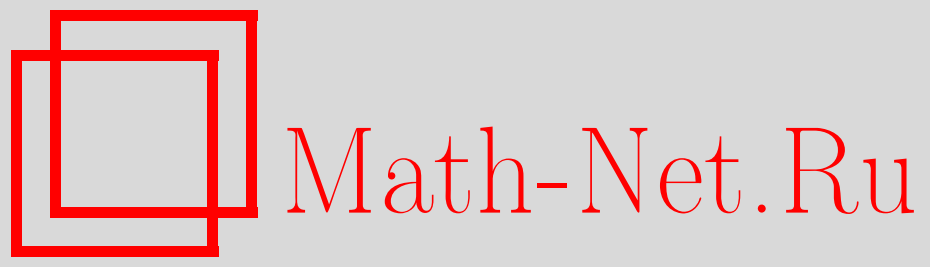

Л. Ашкинази, Механика невидимого, Квант, 2018, номер 11, 10-16

DOI: https://doi.org/10.4213/kvant20181102

Использование Общероссийского математического портала Math-Net.Ru подразумевает, что вы прочитали и согласны с пользовательским соглашением http://www.mathnet.ru/rus/agreement

Параметры загрузки:

IP: 34.227 .88 .159

26 апреля 2023 г., 18:33:16

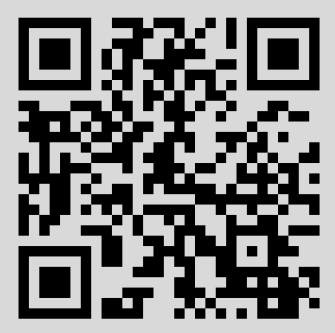




\section{Механика невидимого}

\section{Л.АШКИНАЗИ}

\section{Подчинение законам}

Bce, что мы видим вокруг себя, подчиняется законам механики. Вы легко назовете множество примеров, причем, в соответствии со школьным курсом физики, эти примеры можно разделить на несколько групп. Связанные с движением - небесных тел и транспортных средств; со столкновениями - в технике и спорте; с равновесием - в спорте, технике, строительстве; а также с прочностью и жесткостью вещей и сооружений. Все это мы видим вокруг себя. Но и то, что мы не видим, ведет себя тоже в соответствии с законами механики - силы и механические напряжения в материале лопаток турбин самолетного двигателя и в жестком диске компьютера описываются одними и теми же формулами. Вы вполне можете оценить эти напряжения, если сообщить вам все необходимые (кстати, какие?) параметры. Но то, что быстро вращается и поэтому должно подвергаться действию сил, создающих необходимые ускорения, - это еще далеко не все. Кровь в сосудах, воздух в легких все это движется под действием соответствующих сил. И отдельные клетки, перемещающиеся внутри наших организмов, тоже. Более того, у бактерий есть несколько механизмов перемещения, и они не все еще установлены.

В этой же статье будет рассказано о применении механики в разнообразных электронных приборах - в счетчиках Гейгера, в механотронах, в мощных электронных лампах, в просвечивающих электронных микроскопах и сканирующих туннельных микроскопах, а также в прибоpax, для которых еще не придумано и названия. Причем будет рассказано не просто о том, что детали должны быть

DOI: https://doi.org/10.4213/kvant20181102 прочными, а о чем-то более интересном и менее очевидном.

\section{Счетчик Гейгера}

Принцип работы этого прибора вы знаете из учебника. В данном случае нам важно, что давление газа внутри существенно меньше атмосферного, поэтому на стенки счетчика действует сила. Нейтронам и $\gamma$-излучению стенки не помеха, но если мы хотим, чтобы прибор реагировал на $\beta$-частицы с относительно малой энергией и на $\alpha$-частицы, то где-то должно быть сделано окно, которое будет их пропускать, и оно должно быть тонким.

Попробуем оценить возможную толщину такого окна. Если атмосферное давление $p$, а диаметр окна $d$, то сила, действующая на окно, равна $p \pi d^{2} / 4$. Примем толщину окна равной $h$ и будем считать, что сила приходится на максимальное сечение материала окна, равное $\pi d h$. Тогда получается, что напряжение в материале составляет $p d /(4 h)$, а минимальное допустимое значение толщины равно $h=p d /(4 \sigma)$, где $\sigma-$ максимальное допустимое механическое напряжение в материале окна. Полагая $p=0,1 \mathrm{MПа,} d=$ $=1 \mathrm{~cm}, \sigma=0,3$ ГПа, находим $h=1$ мкм. Прочность здесь взята для бериллия и слюды, из которых часто и делают окошки. Окошко толщиной в 1 мкм сделать можно, но оно будет работать «на пределе» и надежность у прибора станет недопустимо малой. Поэтому окошко делается толщиной в несколько микрон. На фото 1 и 2 показаны два счетчика Гейгера - c окошком из бериллия и из слюды. Поскольку слюда прозрачна, на окошко положена кнопка - чтобы сделать наглядным присутствие окошка. В данном случае механические свойства материала окна прямо определяют возможности прибора. Чем прочнее материал окна, тем оно может 


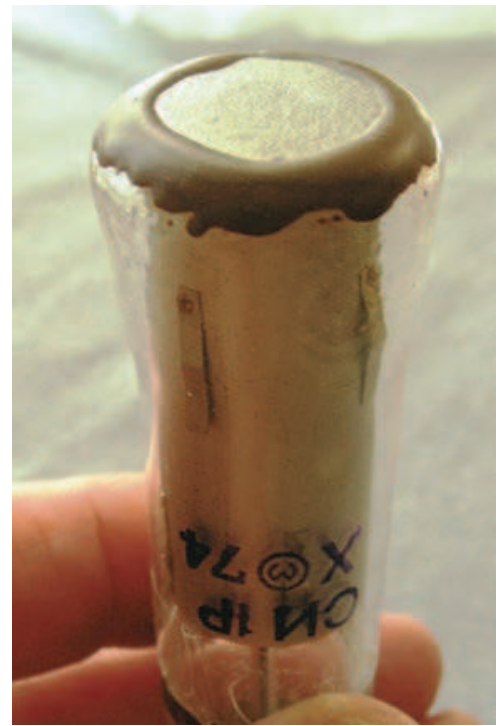

Фото 1. Счетчик Гейгера с окошком из бериллия

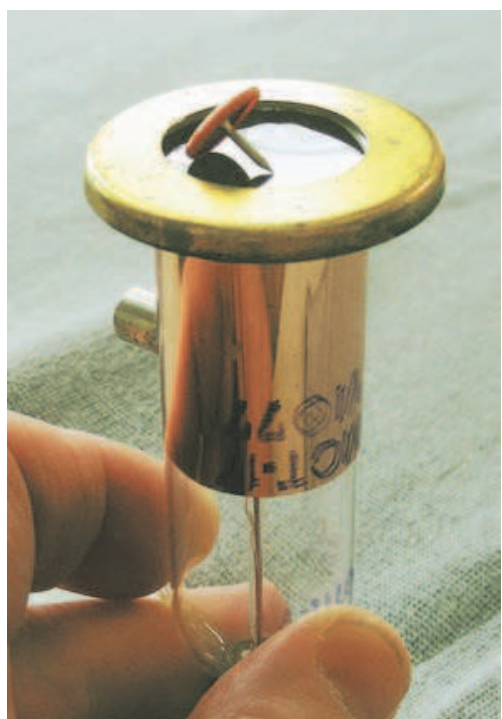

Фото 2. Счетчик Гейгера с окошком из слюды

быть больше - это увеличивает чувствительность прибора или тоньше - это расширяет диапазон энергий регистрируемых частиц в сторону меньших энергий. Потому что чем меньше энергия, тем меньше глубина проникновения частицы в материал. С этой проблемой мы скоро встретимся - в электронном микроскопе. А пока что вернемся к окнам.

\section{Окно для энергии}

Электронно-вакуумные приборы, усиливающие или генерирующие электромагнитные волны, имеют внутри себя вакуум - чтобы электроны могли двигаться свободно. А снаружи присутствует атмосфера. Значит, нам опять нужно окно, которое выдержит разность давлений и пропустит электромагнитную волну. В данном случае проблема облегчается тем, что в хорошем диэлектрике волны с длиной волны порядка сантиметра и более (а это вся связь, телевидение, радиолокация) затухают слабо, поэтому окно может быть толще. Однако на границе диэлектрика происходит отражение - часть энергии возвращается в прибор. Когда-то в качестве материала «вывода энергии» применялась опять же слюда (фото 3), сейчас

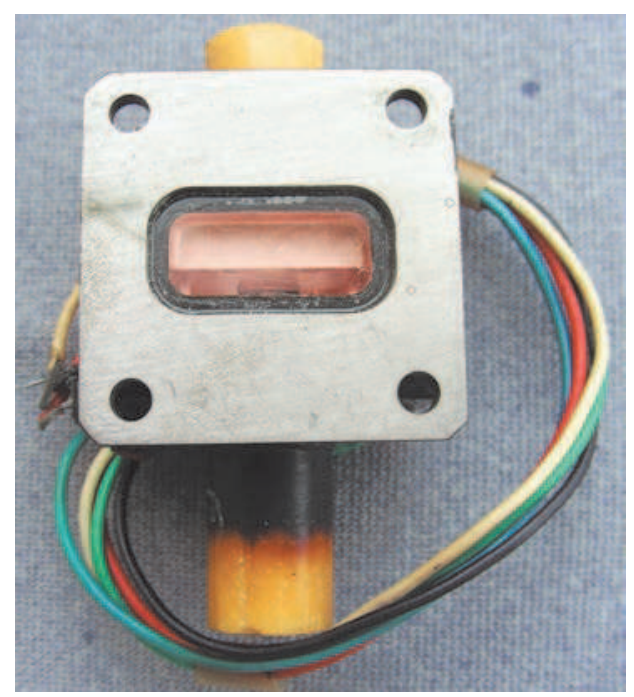

Фото 3. Электронно-вакуумный прибор сокошком из слюды

это обычно керамика (фото 4). Вытянутая вдоль волновода форма керамики (верхний объект на фото 4) используется для уменьшения отражения электромагнитной волны.

Кстати, насчет того, что «снаружи присутствует атмосфера». Когда начались полеты в космос, некоторые вздохнули облегченно - проблемы с созданием вакуума в электронных приборах и выводом энергии решены! Ан нет: оказалось, что 


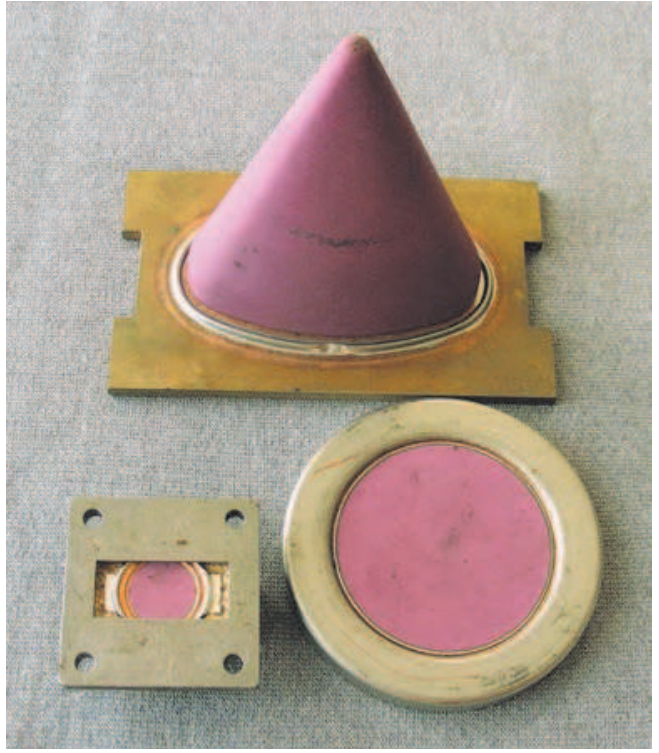

Фото 4. Электронно-вакуумный прибор с керамическим ОКОшком

вакуум в ближнем космосе гораздо хуже того, который должен быть в электронном приборе (от $10^{-7}$ до $10^{-15}$ атм), и баллон прибору все равно нужен. Про Луну и Марс и говорить не стоит - вокруг Луны летает пыль от ударов о ее поверхность микрометеоритов, а что происходит на Mapce, знаете сами. Или посмотрите в учебнике или интернете. Так что в вакуумных приборах чистота, как в дальнем космосе.

\section{Опять окно - для микроскопа}

В просвечивающем электронном микроскопе электронный пучок должен распространяться, не рассеиваясь, поэтому в приборе нужен вакуум. И пучок должен проходить через наш образец насквозь поэтому образец обязан быть тонким. Причем образец не должен портить вакуум, а вакуум не должен портить образец. Первая проблема решается легко: образец маленький, и то, что он выделяет, насосы микроскопа откачают, а со второй проблемой дело обстоит сложнее. Из-за этого в электронном микроскопе нельзя просто так исследовать биообъекты, например живые клетки, - вода мгновенно испаряется, и клетка гибнет.
Однако не будем затрагивать биологию, а обратим свое внимание на компьютеры, роутеры, камеры, смартфоны и прочие гаджеты. Во всех них есть источник энергии - батарейка или аккумулятор. Рассказывать, как и почему важен запас энергии, не надо - это знает каждый, кто срочно искал, куда бы воткнуть зарядное устройство. Поэтому исследования в области улучшения параметров аккумуляторов ведутся непрерывно.

Очень важно, например, понять, как изменяется в процессе заряда и разряда аккумулятора структура его материалов. Возникает нетривиальная задача: сделать аккумулятор толщиной в микроны, чтобы пучок прошил его насквозь. Но это еще не все - в аккумуляторе есть электролит, а в вакууме он (как и жидкость из клетки) мгновенно испарится, и аккумулятор (как и клетка) погибнет. Решение нашла группа под руководством А.М.Абакумова (МГУ, Сколтех) - в их приборе электронный пучок проходил через окно толщиной в доли микрона, сделанное из соединения $\mathrm{Si}_{3} \mathrm{~N}_{4}$. Торможение электронов в твердом теле зависит от концентрации в нем своих электронов, поэтому пробег тем больше, чем меньше атомные номера элементов, из которых состоит преграда. Заметьте, что $\mathrm{Si}, \mathrm{N}, \mathrm{Be}$ и то, из чего состоит слюда, чаще всего мусковит $\mathrm{KAl}_{2}\left[\mathrm{AlSi}_{3} \mathrm{O}_{10}\right](\mathrm{OH})_{2}$, это все верх Периодической таблицы. Разумеется, важно еще, можно ли из такого материала сделать микронную пластинку, какова будет ее прочность и как ее соединить с остальным корпусом. По сравнению со счетчиком Гейгера в случае электронного микроскопа проблема немного облегчается тем, что от площади окна чувствительность метода не зависит, поэтому окно можно сделать поменьше. Но, с другой стороны, в счетчике важно, чтобы частица просто попала внутрь, а в микроскопе важно еще, чтобы электронный луч не рассеивался в материале окна.

\section{Выпусти электрон на волю}

Пробег электрона в веществе зависит от количества встреченных по дороге электронов. Но оно зависит не только от атом- 
ного номера элементов, а еще и от концентрации атомов в пространстве. Поэтому в атмосфере, т.е. в газе, пробег электронов должен быть относительно велик. Действительно, в воздухе при нормальных условиях и при энергии электронов 20 кэВ их пробег составляет около 2 см, а при энергии 20 МэВ - 100 м. Этот диапазон энергий примерно соответствует энергиям электронов при $\beta$-распаде. То, что электроны могут преодолевать заметные расстояния в воздухе, наводит на мысль о возможности их применения для инициирования химических реакций, для обработки материалов, для сварки и т.д. Действительно, такие возможности имеются. Однако, для того чтобы ими воспользоваться, надо сначала отделить электроны от прочих компонентов вещества, потом ускорить, т.е. сообщить им энергию.

Добыть электроны можно посредством термо- или автоэлектронной эмиссии (с этим мы еще встретимся) из твердого тела или жидкости, а можно извлечь их из плазмы газового разряда. Ускорять электроны удобно в вакууме, и тут же возникает проблема выпуска электронного потока в атмосферу. Естественно, выпускают пучок через фольгу из титана (Тi) толщиной в десять и более микрон. Поскольку пучок изначально ускоряется до энергий в сотни килоэлектровольт, его пробег в титане составляет величину порядка сотен микрон, поэтому фольга толщиной в десятки микрон хотя и будет перехватывать часть пучка и греться, но большая часть пучка пройдет через фольгу. Применение именно титана, а не, скажем, бериллия связано с доступностью фольги из титана - она намного дешевле. А что произойдет при попытке пропустить поток электронов через слюду, при том что слюда все-таки перехватит часть электронов, подумайте сами.

А пока обратимся к микроскопам - но к другим.

\section{Сколько атомов может поместиться на острие иглы?}

Если спросить вас, что такое микроскоп, вы ответите, что это нечто такое, посредством чего мы видим что-то маленькое, которое иначе не увидеть. Это правильно, но мы получаем информацию не только при помощи зрения, почему же микроскоп в этом смысле дискриминировали? А если он сообщит нам какую-то информацию о маленьком объекте не в виде оптического сигнала? Ограничение связано только с традицией, мы привыкли «видеть» объекты - их расположение, форму, рельеф поверхности и ее «оптические» свойства, т.е. цвет, коэффициент отражения, блеск и т.д. Перечисленные параметры не независимы, они связаны сложно и интересно; например, подумайте, что такое «блеск» и от чего он зависит. Но сейчас нам важно другое: каким бы способом микроскоп не получал информацию об объекте, он должен представить ее в виде картинки, на которую мы посмотрим. Картинка эта плоская, но часто создающая у нас в мозгу объемное изображение; возможен и микроскоп, который создает настоящее объемное изображение.

А вот на этап, как говорится, «визуализации» надо посмотреть внимательнее. Ибо то, что нам показывает микроскоп, а именно расположение, форма, поверхность объекта, далеко не всегда то, что мы бы увидели, если бы объект увеличился в миллион или миллиард раз. Например, потому, что в области нанометров изменяется смысл понятий «форма» и «поверхность», а понятия «цвет» и «блеск» вообще пропадают. Даже когда привычный электронный микроскоп (человек работает с ним с 1931 года) показывает нам картинку, надо понимать и помнить, как он ее получал и преобразовывал. (Если мы вообще хотим что-то понять, а не просто поахать и поохать.)

Ионный проектор - вещь, в принципе, простая. Поместим в вакуум металлическую иглу и подадим на нее высокое напряжение. Рядом с острием напряженность поля такова, что оставшиеся в вакууме атомы газа ионизируются, а ионы ускоряются полем, летят до люминесцентного экрана и создают изображение. Ионизация происходит тем чаще, чем выше напряженность поля, а она выше рядом с отдельными атомами, торчащими из ост- 


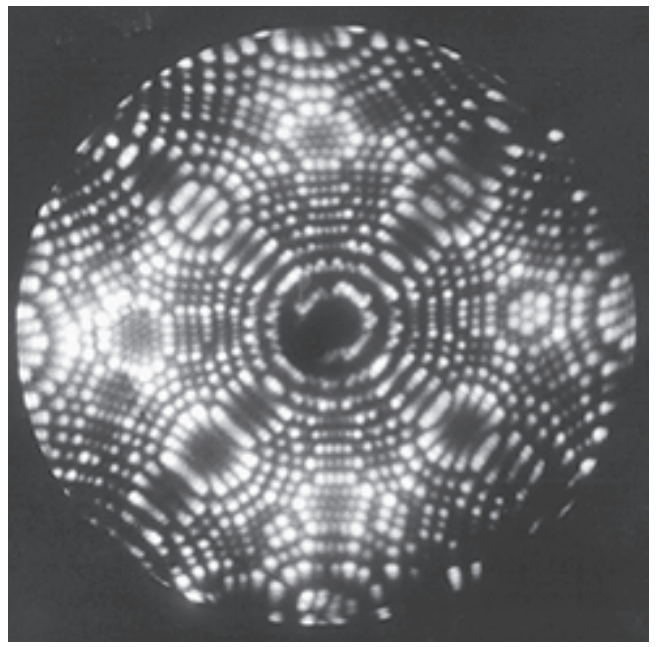

Фото 5. Металлическая решетка в атомном изображении

рия. Вот и получаем мы на экране изображение решетки металла с атомным разрешением (фото 5). Но важно помнить, что в данном случае мы видим не атомную, а электронную плотность. А еще надо не забывать про закон Кулона и прочность кристаллической решетки - соответствующая сила может оторвать от иглы отдельные атомы («полевое испарение») или разрушить иглу. При вакуумном пробое, а сейчас мы о нем поговорим, именно это и происходит.

\section{Вакуумный пробой}

Когда говорят об электрическом пробое диэлектрика, имеется в виду следующее. Берем кусок диэлектрика, прикладываем к нему электрическое напряжение и начинаем это напряжение увеличивать. Идеальных диэлектриков не бывает, поэтому появляется ток - поначалу маленький. А раз есть ток и напряжение, значит, есть мощность. Если мощность умножить на время, получим энергию - значит, в диэлектрике должно что-то происходить. И действительно, в какой-то момент ток скачком возрастает, диэлектрик перестает быть диэлектриком. Причем что-то происходит с самим материалом диэлектрика, с веществом. Но в вакууме вещества нет! И то, что происходит при вакуумном пробое, может происходить только с материалом электродов. А как материал электродов попадает в зазор?

Собственно, путь для этого один - испарение и заполнение парами материала электродов вакуумного зазора. А уж в этом паре происходит пробой, зажигается разряд (если хватает мощности, горит дуга), прибор разрушается. Осталась мелочь понять, кто испаряет материал электрода.

Для этого есть два механизма. Первый механизм состоит в следующем. При высокой напряженности поля начинается автоэлектронная эмиссия одного из электродов. Вылетевшие из него электроны достигают противоположного электрода и выделяют на нем свою энергию. Напряженность поля выше всего на остриях, вот почему полируют электроды высоковольтных вакуумных конденсаторов. Второй механизм таков: электрическое поле отрывает кусок материала от электрода (поскольку его поверхность заряжена), этот кусок летит через зазор, всю дорогу ускоряясь (второй закон Ньютона в действии), и отдает свою энергию другому электроду, а далее - нагрев, испарение и пробой в парах. Поэтому электроды стараются делать из прочных металлов.

Между прочим, вакуумные конденсаторы - далеко не единственная и даже не основная ситуация, когда мы имеем вакуум и высокое напряжение. Так происходит почти во всех мощных электровакуумных приборах - а это и космическая связь, и радиолокация, и ускорительная техника, и телевидение... Даже токамак без таких приборов не заработает!

\section{Еще два микроскопа: сканирующий туннельный и атомно-силовой}

Преимущество этих двух микроскопов в том, что им не нужен вакуум, который разрушает многие интересные объекты (например, биологические). Если поднести к поверхности объекта на маленькое расстояние иглу и подать на нее напряжение, между иглой и поверхностью (если она хотя бы плохой, но проводник) начнет протекать ток - тот самый автоэлектронный ток, с которого иногда начинается вакуумный пробой. Чем игла острее, тем 
выше пространственное разрешение, и оно может достигать десятых долей межатомного расстояния в решетке! Возникающий ток очень сильно зависит от расстояния между поверхностью и иглой, и мы можем измерить это расстояние с высокой точностью. Но расстояние до чего именно - мы ведь ни в каком смысле не касались атомов? Это будет как раз «расстояние до электронов», т.е. мы получим профиль электронной плотности над поверхностью. Пример для кремния показан на фото 6.

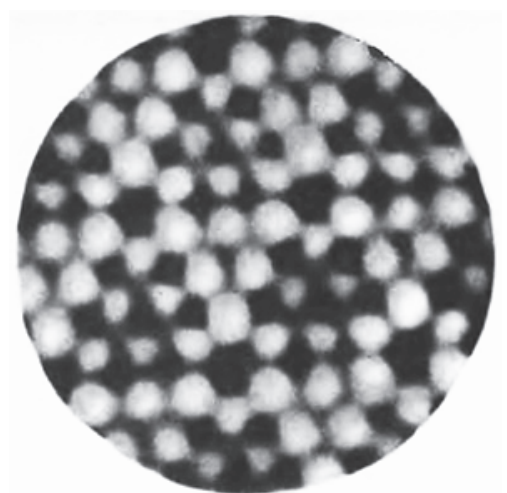

Фото 6. Профиль электронной плотности над поверхностью кремния

Но, как вам известно, между атомами действуют силы - притяжения на большом расстоянии и отталкивания на малом. Атомы в молекуле располагаются в среднем на таком расстоянии друг от друга, когда сумма этих сил равна нулю. Поэтому, если мы будем подводить иглу к поверхности, на нее начнет действовать сила. Эту силу измеряют по изгибу «кантилевера» - балки, на которой закреплена игла. А это как раз и есть механика, причем основы теории изгиба балок заложили не абы кто, а Эйлер и Бернулли в XVII-XVIII веках.

Заметим, что атомно-силовые микроскопы XXI века работают хитрее. Они приближаются к поверхности, слегка вибрируя, а на параметры этих колебаний и влияют силы, действующие на подползающую к поверхности иглу... Вот это уже современная механика на самом переднем крае наук о поверхности, как сейчас модно говорить - нанонаук. О них мы еще поговорим.

\section{Механотрон}

Чем мы измеряем перемещения? А это смотря какие и с какой точностью. Но прежде всего на ум приходят механические и оптические средства измерений рулетки, линейки, лазерные дальномеры, интерферометры. Обработка результатов измерения осуществляется нынче довольно часто компьютерами, а чтобы сообщить компьютеру результат измерений, нужно сначала получить его в виде электрического сигнала, потом преобразовать в цифровую форму. Второе - вещь освоенная, соответствующие устройства называются аналого-цифровыми преобразователями (АЦП). А как сделать, чтобы перемещение чего-то откликалось электрическим сигналом?

Один из вариантов - перемещать ферромагнитный сердечник, изменяя индуктивность катушки, другой - перемещать пластину конденсатора, изменяя емкость. Далее использовать индуктивность и емкость можно по-разному, например через реактивное сопротивление или резонансную частоту контура (формула Томсона). Но есть и другой, менее распространенный способ - перемещать анод электронной лампы. При этом изменяются ее параметры, например анодный ток при определен-

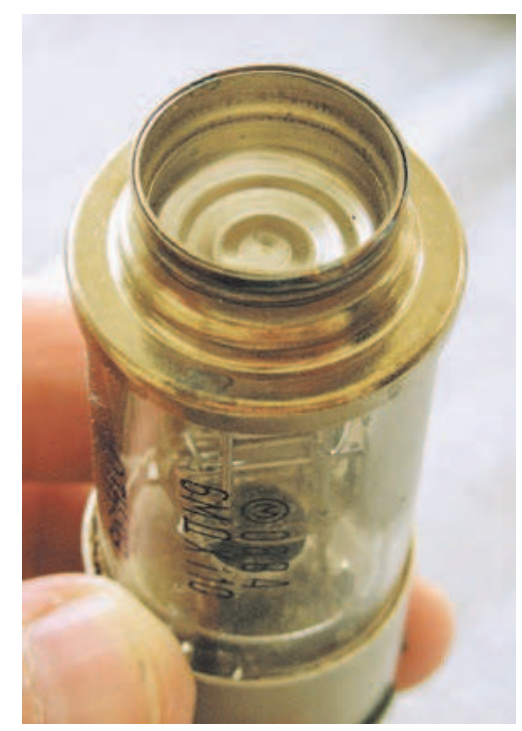

Фото 7. Механотрон 
ном анодном напряжении. Соответствующая лампа называется «механотрон» (фото 7 ), ее стеклянный баллон спаян с металлической рамкой, в рамку впаяна мембрана (ее край виден на снимке), а к мембране изнутри и прикреплен анод. При нажатии на мембрану анод перемещается. Параметры лампы как преобразователя силы в ток зависят от жесткости мембраны, а как преобразователя перемещения в ток - не зависят. Понимаете, почему это так?

\section{Изотопный мотор}

Один из экзотических источников электроэнергии - изотопная батарея. Простейший вариант - конденсатор в вакууме, от его пластин сделаны выводы, на одну из пластин нанесен $\beta$-активный изотоп. Электроны вылетают, попадают на противоположную пластину и через нагрузку возвращаются обратно. А что происходит, если нагрузка не присоединена?

Представим себе ситуацию, когда внешней нагрузки нет, но зато одна из пластин сделана гибкой. Тогда по мере увеличения заряда на ней эта пластина начнет изгибаться, и, если она сумеет коснуться другой пластины, конденсатор разрядится, пластина выпрямится, и все начнется сначала. Параметры такого мотора зависят, естественно, от энергии электронов и их тока, от геометрии системы (размеров пластины и зазора) и параметров материала (модуля Юнга). Можете на досуге попробовать решить эту задачу.

Вполне возможно, что когда-нибудь такие микро- или, скорее, нанодвигатели будут применяться. Тем более, что начали появляться идеи использования этих движений для генерации электроэнергии например, сделав пластину из сегнетоэлектрика. Впрочем, обычная изотопная батарея и так уже является источником электроэнергии.

\section{Нано: электроника и трение}

Законы физики одинаковы на всех уровнях - от межатомных расстояний в твердом теле, до межгалактических у нас над головой. Но проявляются они по-разному. И то, на что мы привычно не обращаем внимания, размышляя о процессах в твердом теле и при контакте твердях тел, становится определяющим в космосе например, гравитация. А что-то остается столь же важным - например, диффузия в твердим теле и диффузия излучения в звездах. Правда, это диффузия чего-то другого...

Опускаясь в мир нанорасстояний, мы не должны забывать про механику, но относительная роль разных ее аспектов может измениться. Простейший пример: объем тела зависит от его линейных размеров в кубе, а поверхность - в квадрате, поэтому роль поверхностных эффектов, например трения, возрастает. И вообще, начинает происходить странное: незаряженные поверхности притягиваются, звук передается через вакуум, иначе передается тепло, возникает бесконтактное трение... Но не спешите выкидывать школьные учебники. Все это становится существенным только на расстояниях, сравнимых с межатомными, и только тогда, когда вы займетесь Серьезной Физикой.

\section{Тут продвинутый школьник...}

...который днюет не выпуская из рук кодификатор ЕГЭ, а ночует в обнимку с университетским курсом физики, спросит: а зачем мне было это читать? Я это и так все знаю. Ну, почти все...

На это есть два ответа - один обидный, а другой - по существу. Обидный ответ вот: это вам так кажется, что знаете. А преподаватель задаст два-три вопроса, и вы сами поймете, что умение делать умные глаза и кивать в нужных местах - это не знание. Ответ по существу вот: написано это было мною, а прочитано вами для того, чтобы вы поняли - мир не делится на механику, термодинамику, электричество и далее по списку. Физику надо знать всю. Точнее - всю ширину, а в глубину - в пределах школьного, потом и серьезного университетского курса.

А электронные приборы - еще не самое страшное. Исследование элементарных частиц и поведение звезд и галактик - так и там рулит Ньютон. Прямо из своего XVII века. 